This is the final peer-reviewed accepted manuscript of:

Malgorzata Anita Bryszewska, Lidia Tomás-Cobos, Elisa Gallego, Mari Paz Villalba, Daniel Rivera, Danielle Laure Taneyo Saa, Andrea Gianotti. "In vitro bioaccessibility and bioavailability of iron from breads fortified with microencapsulated iron"

which has been published in final form in LWT Volume 99, January 2019, Pages 431437

The final published version is available online at:

https://doi.org/10.1016/i.lwt.2018.09.071

(C) 2018 Elsevier. This manuscript version is made available under the Creative Commons Attribution-NonCommercial-NoDerivs (CC BY-NC-ND) 4.0 International License (http://creativecommons.org/licenses/by-nc-nd/4.0/) 


\title{
In vitro bioaccessibility and bioavailability of iron from breads fortified with microencapsulated iron
}

\author{
Malgorzata Anita Bryszewska ${ }^{\mathrm{a}, *}$, Lidia Tomás-Cobos ${ }^{\mathrm{b}}$, Elisa Gallego ${ }^{\mathrm{b}}$, MariPaz Villalba ${ }^{\mathrm{b}}$, \\ Daniel Rivera ${ }^{\mathrm{b}}$, Danielle Laure Taneyo Saa ${ }^{\mathrm{c}}$, Andrea Gianotti ${ }^{\mathrm{c}}$ \\ ${ }^{a}$ Faculty of Biotechnology and Food Sciences, Lodz University of Technology, Lodz, 90-924, Poland \\ ${ }^{\mathrm{b}}$ AINIA Technological Centre, c/Benjamín Franklin 5-11, Paterna, 46980, Valencia, Spain \\ ${ }^{\mathrm{c}}$ Department of Agri-Food Sciences and Technologies, University of Bologna, Piazza Goidanich 60, 47521, Cesena, Italy
}

\begin{abstract}
A B S T R A C T
Iron deficiency is the most prevalent mineral deficiency in the world. Food fortification offers an alternative to standard oral iron therapy, which often causes unpleasant side effects. In this study, bread was fortified with either ferrous sulphate or ferrous fumarate. To prevent undesired organoleptic changes in colour, odour and taste, iron compounds were introduced in the form of microcapsules. Eight types of bread were prepared using conventional fermentation or sourdough and fortified with one of four types of microcapsule. The in vitro bioaccessibility and bioavailability of the iron were determined using the human epithelial adenocarcinoma cell line Caco-2, preceded by digestion in a dynamic gastrointestinal digester, which mimics the upper gastrointestinal tract of an adult human. The bioaccessibility of the iron after digestion of the fortified breads varied from 41.45 to $99.31 \%$. The iron transport efficiency varied widely, from 1.16 to $13.78 \%$. Generally, both bioaccessibility and transport efficiency were higher in the samples of breads prepared by conventional fermentation. The mRNA expression of DMT1 and IREG1, cellular iron transporters which serve as molecular markers of iron movement across the intestinal border, was not statistically significant.
\end{abstract}

Keywords:

Iron deficiency

Iron fortified food

Microencapsulation

Iron fortified bread

\section{Introduction}

Mineral malnutrition is prevalent in both industrial and developing countries, with iron deficiency being the single most widespread cause. It is estimated that $60 \%$ of the world's population is deficient in iron, while $33 \%, 30 \%$ and $15 \%$ are deficient in zinc, iodine and selenium, respectively (Castillo-Duran \& Ruz, 2004.)' (International Zinc Nutrition Consultative Group (IZiNCG) et al., 2004). According to the WHO, nutritional iron deficiency affects 1.5-2 billion people worldwide (Development, 2001)' (Worldwide prevalence of anaemia 1993-2005," 2015) Okhee, 2011; World Development Report 1993; WHO, 2001; WHO, 2015. Iron deficiency is a general term for suboptimal levels of iron in the body for health and is associated with diminished work productivity, lower immunity and impaired cognitive development. Iron is essential for life, due to its role in nearly all redox reactions and in the transportation of oxygen through the body. It is also a vital component in several enzymes (Tandara \& Salamunic, 2012). Iron deficiency can be caused by inadequate iron intake, compromised bioavailability and increased iron losses, or by a combination of these
(Zimmermann \& Hurrell, 2007). To combat micronutrient malnutrition, three cost-effective strategies can be applied: food fortification, food enrichment and diet supplementation (World Development Report, 1993). The fortification of foods (addition of nutrients to foods irrespective of whether or not those nutrients were originally present in the food) is often regarded as the most cost-effective long-term approach to reducing iron deficiency. It also has no side effects, or fewer than supplementation (Hurrell, 1997)' (Gera, Sachdev, \& Boy, 2012). However, direct iron food fortification may result in undesirable organoleptic changes in the colour, odour and taste of foods (Gaucheron, 2000). Moreover, iron may interact with product components (lipids and protein), which can decrease its bioavailability, defined as the proportion of a nutrient that is absorbed and used in normal bodily functions (Hurrell \& Egli, 2010). Iron encapsulation can help to overcome unwanted sensory changes in fortified foods, while also reducing the interaction of Fe with food components and increasing Fe bioavailability (Gharibzahedi \& Jafari, 2017)' (Gera et al., 2012)' (Zlotkin, Arthur, Antwi, \& Yeung, 2001).

Iron absorption is regulated not only by nutritional factors, but also

\footnotetext{
* Corresponding author.

E-mail addresses: malgorzata.bryszewska@p.lodz.pl (M.A. Bryszewska), ltomas@ainia.es (L. Tomás-Cobos), egallego@ainia.es (E. Gallego), mpvillalba@ainia.es (M. Villalba), jdrivera@ainia.es (D. Rivera), saalaure@gmail.com (D.L. Taneyo Saa).
} 
by physiological agents, such as bioactive hepcidin peptide, iron importer divalent metal transporter 1 (DMT1) and the cellular iron exporter ferroportin-1 (IREG1) (Ganz, 2013). DMT1 is the most important apical uptake transporter of inorganic iron in enterocytes, which import ferrous iron. DMT1 is essential for normal iron homeostasis (Ganz, 2013). IREG1 is a transmembrane protein, which transports iron from the inside of cells to the outside environment. It is the molecular target of hepcidin, which modulates the uptake of iron at the apical membrane of enterocytes (Nemeth et al., 2004)' (Donovan et al., 2005). In vitro models have been proposed for bioavailability assessment. Caco- 2 cells similarly express DMT1, transferrin receptor (TfR) and iron-regulatory protein (IRP-1, IRP-2) to human enterocytes. Iron uptake in Caco-2 cells has been shown to be time and concentration dependent, to exhibit saturation kinetics and to be inversely dependent on $\mathrm{pH}$ (Tapia, Arredondo, \& Núñez, 1996)' (Tandy et al., 2000). In combination with a simulated digestion procedure, Caco- 2 cells are considered a useful model for predicting nutrient availability and uptake (Fairweather-Tait et al., 2005).

The aim of this study was to investigate bioaccessibility and bioavailability of iron from breads prepared by conventional fermentation or sourdough fortified with encapsulated either ferrous sulphate or ferrous lactate, using a dynamic gastrointestinal digester as in vitro model.

\section{Materials and methods}

\subsection{Materials}

All reagents used were of reagent grade. Milli Q distilled deionized water was used throughout. The glass and polyethylene materials were soaked in concentrated nitric acid for $24 \mathrm{~h}$ and then rinsed with distilled deionized water before they were used. Working solutions of enzymes were prepared immediately before use. Alpha-amylase (from Aspergillus oryzae, A-9857, $\geq 150$ units/mg protein), pepsin (from porcine gastric mucosa, P-7012, $\geq 2500$ units/mg protein), trypsin (from bovine pancreas, T-9201, $\geq 7500$ BAEE units/mg solid), pancreatin (from porcine pancreas, P-1750, 4 x USP specification) and bile (porcine bile extract, B-8631) were purchased from Sigma (St Louis, USA). Lipase (Rhizopus lipase, F-AP15, $\geq 150.000 \mathrm{U} / \mathrm{g}$ ) was obtained from Amano Enzyme, Inc. (Nagoya, Japan). Medium EBSS, fetal bovine serum (FBS), penicillin, streptomycin and L-glutamine were obtained from GE Healthcare (Little Chalfont, UK). Non-essential amino acids (NEAA), Hepes, sodium piruvate and fungizone were obtained from Thermo Fisher Scientific (Waltham, MA, USA). HBSS buffer, glucose and CelLyticä M reagent were sourced from Sigma (St Louis, USA).

\subsection{Microencapsulated iron}

The encapsulated ferrous sulphate and encapsulated ferrous lactate were prepared by EPSA (Valencia, Spain) and AINIA, Centro Tecnológico, using a method described in detail elsewhere (Rivera, Gallego, Villalba, \& Gianotti, 2014). A Briefly, a suspension of termoresistan modified starch (TMS) was prepared in deionized water, with a concentration of 85 to $65 \% \mathrm{~g} / \mathrm{g}$. The ferrous sulphate or ferrous lactate was suspended in the TMS solution, to a concentration of $15-35 \%(\mathrm{~g} / \mathrm{g})$ and spray dried (Dryer Mini spray-dryer B-290, Büchi, Switzerland).

\subsection{Experimental breads}

The control bread was made from a white wheat flour (type 650). The fortified breads were made using an iron-fortified mix of the wheat flour and one of four preparation of encapsulated iron. The composition of each of the microcapsules is described in Table 1.

Mass of a microcapsules was adjusted to obtain similar level of enrichment, that was about $24 \mathrm{mg}$ of $\mathrm{Fe}$ in $100 \mathrm{~g}$ in each of bread types.
Table 1

Composition of microcapsules. Ascorbic acid, used in concentration 25g/100g of preparation.

\begin{tabular}{llll}
\hline Microcapsule & Iron source & Ascorbic Acid & Total iron content $[\mathrm{g} \mathrm{Fe} / 100 \mathrm{~g}]$ \\
\hline M1 & $\begin{array}{l}\text { ferrous } \\
\text { sulphate }\end{array}$ & No & $11.28 \pm 0.49$ \\
M2 & $\begin{array}{l}\text { ferrous } \\
\text { sulphate }\end{array}$ & Yes & $8.28 \pm 0.38$ \\
M3 & ferrous lactate & No & $5.87 \pm 0.15$ \\
M4 & ferrous lactate & Yes & $4.49 \pm 0.11$ \\
\hline
\end{tabular}

The breads were made according to a procedure developed and optimized at the University of Bologna (UNIBO). The dough for bread made by conventional fermentation was fermented for $45 \mathrm{~min}$ at a controlled temperature $\left(30^{\circ} \mathrm{C}\right)$ and then portioned. The pieces were fermented for another $45 \mathrm{~min}$ under the same conditions, then baked at $195^{\circ} \mathrm{C}$ for $45 \mathrm{~min}$. The sourdough breadmaking process used compressed yeast and lactic acid bacteria belonging to the Department of Agricultural and Food Science and Technology (DISTAL) at Bologna University (Italy): Lactobacillus plantarum (98a), Lactobacillus sanfranciscensis (BB12) and Lactobacillus Brevis (3BHI). The sourdough was prepared from a $0.01 \%$ single-strain starter. The starter was added to equal parts of water and wheat flour, giving a dough yield of 250 (dough weight 100/flour weight). The coarse-grain mixed strain starter was homogenously dispersed in the flour and the single-strain starter was dispersed in the water. The dough was mixed thoroughly for $1 \mathrm{~min}$, poured into a large beaker, covered and placed in an incubator at $30{ }^{\circ} \mathrm{C}$ for $24 \mathrm{~h}$. All samples were obtained from the same batch. Ten experimental breads were obtained: four breads were prepared by conventional fermentation and fortified by one of four microcapsules (CFM1; CFM2; CFM3 and CFM4). Another four breads were prepared by sourdough fermentation with addition of one type of microcapsules (SFM1; SFM2; SFM3 and SFM4). Additionally, two control breads without iron fortification were prepared using sourdough or conventional breadmaking process.

Composition of control breads is presented in Table 2. Analysis of the humidity, fat content and content of soluble sucrose/saccharose in the breads was performed according to Polish standard norm ref. no PNA-74108:1996, Bakery products - testing methods. Protein content was calculated based on nitrogen content, determined using the Kjeldahl method (AOAC 950.36-1950, Protein in bread). The ash residue of the flour was measured using AOAC Official method 923.03. Total dietary fiber was quantified using an assay kit (Sigma, St. Louis).

\subsection{Dynamic gastrointestinal digestion}

A dynamic gastrointestinal digester (DGD) was used to simulate

Table 2

Component analysis of control breads. All values are given in respect to the fresh bread mass." The sourdough was made with $1200 \mathrm{~g}$ of flour and $1800 \mathrm{~g}$ of water.

\begin{tabular}{|c|c|c|c|}
\hline \multicolumn{2}{|c|}{ Sample/Breads } & \multirow{2}{*}{$\begin{array}{l}\text { conventional } \\
\text { fermentation }\end{array}$} & \multirow{2}{*}{$\begin{array}{l}\begin{array}{l}\text { sourdough } \\
\text { fermentation }\end{array} \\
2800\end{array}$} \\
\hline Bread recipe & Flour $[\mathrm{g}]$ & & \\
\hline & Water $[\mathrm{g}]$ & 3040 & 1100 \\
\hline & Sourdough $[g]$ & -- & $3000^{*}$ \\
\hline & Yeast $[\mathrm{g}]$ & 160 & 160 \\
\hline & Salt $(\mathrm{NaCl})[\mathrm{g}]$ & 80 & 80 \\
\hline \multicolumn{2}{|c|}{ Humidity [g 100g-1] } & $42.02 \pm 0,01$ & $45.11 \pm 0.03$ \\
\hline \multicolumn{2}{|c|}{ Proteins $\left[\mathrm{g} 100 \mathrm{~g}^{-1}\right]$} & $8.34 \pm 0.61$ & $7.94 \pm 0.24$ \\
\hline \multirow{2}{*}{\multicolumn{2}{|c|}{ Fat $\left[g 100 g^{-1}\right]$}} & $1.66 \pm 0,25$ & $1.37 \pm 0.28$ \\
\hline & \multicolumn{3}{|c|}{ Carbohydrates } \\
\hline \multicolumn{2}{|c|}{ Total $\left[\mathrm{g} 100 \mathrm{~g}^{-1}\right]$} & 46.64 & 44.26 \\
\hline \multicolumn{2}{|c|}{ Insoluble (fiber)* $\left[\mathrm{g} 100 \mathrm{~g}^{-1}\right]$} & $2.11 \pm 0.16$ & $1.91 \pm 0.14$ \\
\hline \multicolumn{2}{|c|}{ Ash $\left[\mathrm{g} 100 \mathrm{~g}^{-1}\right]$} & $1.63 \pm 0.04$ & $1.87 \pm 0.04$ \\
\hline \multicolumn{2}{|c|}{$\mathrm{NaCl}\left[\mathrm{g} 100 \mathrm{~g}^{-1}\right]$} & $1.10 \pm 0,03$ & $1.12 \pm 0,02$ \\
\hline
\end{tabular}


digestion of the breads. Developed at AINIA, Centro Tecnológico (Valencia, Spain), the multi-compartmental, computer-controlled DGD mimics the upper gastrointestinal tract of human adults. The dynamics of peristaltic mixing, gastric emptying and intestinal transit times, as well as gastric and intestinal $\mathrm{pH}$ values, were simulated in a computercontrolled process (Marteau et al., 1990)' (Minekus et al., 1995). First, the samples were homogenized twice using an Ultra-Turrax with $100 \mathrm{~mL}$ of gastric electrolyte solution $\left(\mathrm{NaCl}, \mathrm{CaCl}_{2}\right.$ and $\mathrm{NaHCO}_{3}$ ) for $10 \mathrm{~s}$ (8000 rpm). Digestion was carried out with $50 \mathrm{~g}$ of bread or $50 \mathrm{~g}$ of water (for the blank). Mouth digestion was started by the addition of alpha-amylase (9600 units) and citrate buffer $(\mathrm{pH}=6)$ up to final weight of the mixture $300 \mathrm{~g}$. The process was continued for $1 \mathrm{~min}$. The digested sample was then introduced into the gastric compartment, which contained $5 \mathrm{~mL}$ of gastric juice composed of gastric electrolytes, pepsin solution $(0.3 \mathrm{mg} / \mathrm{mL})$ and gastric lipase solution $(0.2 \mathrm{mg} / \mathrm{mL})$, pre-warmed to $37^{\circ} \mathrm{C}$. The $\mathrm{pH}$ was controlled continuously in the compartments for the stomach (following $\mathrm{pH}$ changes during gastric digestion, from $\mathrm{pH} 5$ to $\mathrm{pH}$ 2) and the small intestine ( $\mathrm{pH} \mathrm{6.5-7),} \mathrm{using}$ secretions of $1 \mathrm{M}$ hydrochloric acid and $1 \mathrm{M}$ sodium bicarbonate, respectively. Simultaneously, $7 \%(\mathrm{~g} / \mathrm{mL})$ of pancreatin solution (cocktail of pancreatic amylase, lipase, ribonuclease, and trypsin) and $2 \%(\mathrm{~g} / \mathrm{mL})$ bile solution were added at a flow rate of $0.5 \mathrm{~mL} / \mathrm{min}$ throughout the experiment. The secretion products (e.g., gastric juice with enzymes, electrolytes, pepsin, bile, pancreatin) were freshly prepared. Gastric and intestinal transit was simulated by opening and closing the peristaltic valves connecting the compartments. All the parameters for in vitro digestion were selected to reproduce the gastrointestinal conditions of a healthy human adult after intake of a solid meal. The transit times were $1 \mathrm{~min}, 2 \mathrm{~h}$ and $6 \mathrm{~h}$ in the mouth, stomach and intestine compartments, respectively (Minekus, Smeets-Peeters, Bernalier, Marol-Bonnin, Havenaar, \& Marteauat al, 1999). The entire process of in vitro dynamic gastrointestinal digestion was performed at $37^{\circ} \mathrm{C}$ in the absence of light and under anaerobic conditions, achieved by injecting nitrogen gas into the system.

\subsection{Caco-2 cell culture}

Caco- 2 cells were obtained as a CacoReady ${ }^{\mathrm{TM}}$ kit (ReadyCell S.L, Spain). The Caco-2 cells were differentiated and polarized $>16$ days after seeding. The cells were seeded on polycarbonate microporous filters in 24-well HTS plates, $6.5 \mathrm{~mm}$ in diameter, $0.33 \mathrm{~cm}^{2}$ in area and with $0.4 \mathrm{~mm}$ pore size. The shipping medium was changed using DMEM $4.5 \mathrm{~g} / 1$ glucose, $10 \% \mathrm{FBS}, 100 \mathrm{u} / \mathrm{mL}$ penicillin and $100 \mathrm{mg} / \mathrm{mL}$ streptomycin on day 18 of the seed.

\subsection{Iron transport in Caco-2 cells}

Experiments were performed from day 21 of the differentiation of the Caco- 2 cells. Before the assays, the cells were treated with medium without FBS. The transepithelial electrical resistance (TEER) was measured to evaluate the state of the cells (membrane integrity). A TEER value of $1.000 \Omega \mathrm{cm}^{2}$ (or higher) indicates that the barrier system is sufficient for an absorption assay (the active membrane surface is $0.33 \mathrm{~cm}^{2}$ ). The TEER values of the cells were between 4500 and $8000 \Omega \mathrm{cm}^{2}$. For the transport assay, the cells were washed three times with HBSS buffer before they were incubated with digested bread. The transwell has two chambers: the apical chamber, which simulates the intestinal lumen, and the basal chamber, which collects the bioavailable iron. The cells were treated with the digested breads in the apical chamber, and with HBSS buffer in the basal chamber. After $2 \mathrm{~h}$, the apical and basal media were collected for iron analysis. The cells were incubated for an additional 3-4 h in media without FBS. The cells were then collected for gene expression analysis. The ratio of the soluble iron present in the basal media to that on the apical side at the end of the incubation period was calculated as the percentage of iron transport. Iron transport and transport efficiency were corrected for the control samples (CFC and SFC, respectively).

\subsection{Analysis of DMT1 and IREG1 mRNA expression}

Total cellular RNA from Caco-2 (CacoReady) was isolated automatically using a Maxwell 16 (Promega) system and a kit for RNA extraction from tissue and mammal cells. The first strand of cDNA was obtained using high-capacity cDNA reverse transcriptase (Applied Biosystem). The cDNA was used as a template for polymerase chain reaction (PCR) amplification using TaqMan polymerase (Applied Biosystem). Commercial primers were used (Applied Biosystem): DMT1 (4331182), IREG1 (4331182) and $\beta$-actine (4326315). Data for DMT1 and IREG1 were normalized to levels of $\beta$-actin mRNA, a constitutively expressed gene. The quantification of gene expression is related with a reference condition by the following formula: $2^{-\boldsymbol{\omega} \Delta \Delta \mathrm{Ct}}(\Delta \mathrm{Ct}=(\mathrm{Ct}$ biomarker gene - Ct internal gen ( $\beta$-actin) and $\Delta \Delta \mathrm{Ct}(\Delta \mathrm{ct}$ sample $-\Delta \mathrm{Ct}$ reference).

\subsection{Measurement of total iron and Fe(II)}

The total concentration of iron in the wet-digested samples was determined using atomic absorption spectrophotometry. The Standard Berghof (Berghof Products + Instruments GmbH Labor Technik, Eningen, Germany) method was applied for microwave digestion of wheat. Briefly, $1 \mathrm{~g}$ or $0.5 \mathrm{~mL}$ samples were digested in $10 \mathrm{~cm}^{-3}$ of concentrated nitric acid and $2 \mathrm{~cm}^{-3}$ of $30 \%$ hydrogen peroxide in closed vessels, in a microwave oven using a three-step digestion program with the temperature raised to $170^{\circ} \mathrm{C}$ and a total digestion time of $25 \mathrm{~min}$. The digested samples were diluted with deionized water and the iron content determined by AAS using a GBC 932 spectrophotometer (GBC Scientific Equipment Pty Ltd., Braeside, Australia), with a hollow cathode lamp for iron, at $248.3 \mathrm{~nm}$. Acetylene and air flow were fine-tuned daily. Standard curves were prepared daily by diluting iron standard reference materials $\left(1000 \mu \mathrm{g}^{\prime} \mathrm{cm}^{-3}\right.$; JT Baker Chemicals, Phillipsburg, NJ, USA) with deionized water to concentrations of between 0 and $10 \mu \mathrm{g}^{\prime} \mathrm{cm}^{-3}$. A certified reference material, Wheat flour - Trace elements (NIMGBW10011) (LGC, standards, Dziekanow Lesny, Poland), was used to test the accuracy of the methods. Iron recovery from whole blood was $97 \%$. During analysis, precautions were taken to avoid contamination of the iron samples.

The presence of $\mathrm{Fe}(\mathrm{II})$ was determined by the formation of blue coordinating compound, by the chelation of Fe(II) with Ferene S reagent (3-(2-pyridyl)-5,6-difurylsulfonic acid-1,2,4-triazine sodium salt) under acidic conditions (Hennessy, Reid, Smith, \& Thompson, 1984). Reduction of iron(III) to iron(II), necessary for iron complexation, was performed at room temperature during $10 \mathrm{~min}$ of incubation using ascorbic acid. The concentration of iron(II) was calculated based on a calibration curve. The response was linear and the correlation coefficients $\left(\mathrm{R}^{2}\right)$ were always greater than 0.996. Typical calibration standards, ranging from 5 to $20 \mu \mathrm{mol} \mathrm{Fe} / \mathrm{L}$, were prepared from the working standard, which was prepared daily. Limit of detection was 0.46 $\mu \mathrm{molFe} / \mathrm{L}$. The spectrophotometric method was used to determine total iron content in the apical fraction of the cellular model samples, because its concentration was too low to be detected using the method described above. These samples also required preconcentration. The volume of the samples was reduced by up to $50-70 \mu \mathrm{l}$ by heating at $60{ }^{\circ} \mathrm{C}$ for $48 \mathrm{~h}$. The volume was corrected to $100 \mu \mathrm{L}$ using a solution of citric acid.

\subsection{Statistical analysis}

Iron concentration, speciation results and mRNA analysis were expressed as the mean \pm SD of three measurements. Statistical analysis was performed using a one-way ANOVA ( $\mathrm{p}<0.05)$ ) with a T test for comparison with the control (*p < 0.05). Statistical analysis of the data from analysis of DMT1 and IREG1 mRNA expression was carried 
out using a one-way ANOVA ( $\mathrm{p}<0.05$ ) with a T test for comparison with the control (*p $<0.05)$.

\section{Results and discussion}

\subsection{Total iron content in breads}

Table 2 shows the total content of iron in each of the conventional and sourdough fermented breads with and without iron fortification. The Fe content was similar in all of the fortified breads, with a mean iron content of $25.36 \pm 2.11 \mathrm{mg} \mathrm{Fe} / 100 \mathrm{~g}$. The exceptions were the breads fortified with M1 (CFM1 and SFM1), for which the mean iron content was $16.92 \pm 1.56 \mathrm{mgFe} / 100 \mathrm{~g}$. The iron content in CFC did not differ greatly from that in other bakery products, although it was lower than in commercially available white wheat bread, which is around 3.5-5 mg Fe/100 g according to the Food Composition Databases (USDA Food Composition Databases, 2017), or 4.19-4.70 mg Fe/100 g as reported in the literature (Khouzam, Pohl \& Lobinski, 2011). Daily intakes of iron from the fortified breads could range from 25.88 to $47.07 \mathrm{mg}$, based on the average consumption of bread in Europe, which is $163.6 \mathrm{~g}$ per day, per person (International Association of Plant Bakers AISBL, 2013). This would constitute $143-262 \%$ of daily intake, considering that the RDI is $18 \mathrm{mg} /$ day for $19-50$ year old women, who are assumed to be one of the principal groups at risk of anemia.

\subsection{Simulated gastrointestinal digestion - iron bioaccessibility}

Iron ingested daily with the diet is absorbed only in a limited extent because body iron metabolism is a semi-closed system. Information regarding total iron content is insufficient, and can be only a starting point for assessing foods as iron sources. It is important to know the bioaccessibility of iron in food - the fraction of the compound that is released from its matrix in the gastrointestinal tract, and which thus becomes available for intestinal absorption (i.e., enters the blood stream) (Benito \& Miller, 1998). In the experimental conditions of a digestion model, bioaccessibility can be calculated as:

$$
=\frac{\text { Soluble Iron (ionic Iron) in the intestinal digestate }\left[\frac{\mathrm{mg}}{100 \mathrm{~g}}\right]}{\text { Total Iron in bread }\left[\frac{\mathrm{mg}}{100 \mathrm{~g}}\right]} \times 100 \%
$$

In our study, a DGD was used to simulate the average physiological conditions in the upper gastrointestinal tract of healthy human adults. The iron concentrations in the intestinal digestate and the bioaccessibility of iron following gastro-intestinal digestion are shown in Table 3. After in vitro gastrointestinal digestion, most of the iron was released from the matrix and was present in the soluble fraction. The bioaccessibility of iron after the digestion of fortified breads varied from 35.99 to $99.31 \%$. CFM1 and CFM3 showed the highest bioaccessibility of Fe, at $95.22 \%$ and $99.31 \%$, respectively. The amount of iron converted to soluble forms under gastrointestinal conditions was much higher than that reported by Khouzam, Pohl, and Lobinski (2011) in a study evaluating the bioaccessibility of essential elements in bread, fruits and vegetables. The authors reported bioaccessibility of iron in Saj bread ranging from 11.8 to $12.8 \%$. The higher values for bioaccessibility observed in our study can be explained by probable and expected difference in dietary fibres content. In our studies white wheat flour was used whereas, in the compared studies bread was made from brown or full wheat flour. Secondly, it can be expected that iron in the Sai bread was in a complex form. Most of iron naturally present in wholewheat flour is present as phytates, salts of phytic acid (Hurrell \& Egli, 2010). It has been well documented that the inhibition of iron absorption is closely related to the content of phytic acid and its salts (Brune, Rossander-Hultén, Hallberg, Gleerup, \& Sandberg, 1992), (Hurrell, Reddy, Juillerat, \& Cook, 2003). On the other hand, iron released from complexes that can be degraded during digestion in the gastrointestinal tract owing to the action of pepsin and hydrochloric acid is present in the ferric form, which has low solubility and bioavailability (Han, 2011). Apparently encapsulation showed a protective effect, probably preventing the interaction of iron with chelators and ligands that create stable complexes and immobilize the element. Among the main dietary inhibitors of iron absorption are oxalic acid, phytates, dietary fibers, as well as polyphenols, (Blanco-Rojo \& Vaquero, 2018).

In vitro Fe bioaccessibility from breads prepared by conventional fermentation or sourdough was compared. It is well known that the fermentation type is important for the sensorial and nutritional quality of bread (Lopez et al., 2003). In this experiment Fe bioaccessibility showed statistically significant differences $(p<0.05)$. In the cases of breads fortified with M1, M2 and M4 the difference in Fe bioaccessibility depending on fermentation type was $28.93,35.09$ and $32.14 \%$, respectively. An extremely large difference of $63.32 \%$ was observed between samples CFM3 and SFM3. These results seem contrary to others published in the literature. A comparison of the availability of minerals, including iron, in baked goods fermented with sourdough or yeast showed that mineral bioavailability was higher in the case of sourdough fermentation than with yeast fermentation (Lopez et al., 2003). This was associated with the degradation of phytic acid by phytases present in the grain raw materials and produced by yeasts and

Table 3

Iron bioaccessibility and transport efficiency from Fe-fortified breads after digestion in a dynamic gastrointestinal digester and incubation with Caco-2 cell. Iron transport and transport efficiency were corrected for the control samples (CFC and SFC, respectively). The results are presented as the means \pm SD; $n=2$. nd - not

\begin{tabular}{|c|c|c|c|c|c|}
\hline & Total iron content & Iron content in the digestate & Bioaccessibility (Fe(II) + Fe(III)) & Iron transport & Iron transport efficiency \\
\hline CFC & $1.27 \pm 0.15$ & $0.19 \pm 0.00$ & 14.96 & nd & nd \\
\hline CFM2 & $24.52 \pm 1.68$ & $18.08 \pm 1.17$ & 73.72 & $18.69 \pm 2.21$ & 13.78 \\
\hline CFM3 & $27.19 \pm 1.74$ & $27.00 \pm 1.64$ & 99.31 & $3.85 \pm 0.59$ & 3.82 \\
\hline CFM4 & $24.29 \pm 1.28$ & $17.87 \pm 0.89$ & 73.59 & $2.24 \pm 0.44$ & 1.65 \\
\hline SFM2 & $23.58 \pm 1.91$ & $9.11 \pm 0.43$ & 38.63 & $5.25 \pm 0.71$ & 2.03 \\
\hline SFM3 & $28.77 \pm 1.07$ & $10.35 \pm 0.26$ & 35.99 & $3.23 \pm 0.99$ & 1.16 \\
\hline SFM4 & $23.84 \pm 0.78$ & $9.88 \pm 0.19$ & 41.45 & $3.72 \pm 0.34$ & 1.54 \\
\hline \multicolumn{3}{|c|}{ Conventional fermentation* } & $85.46 \pm 13.73^{\mathrm{a}}$ & $7.84 \pm 5.32^{\mathrm{a}}$ & $6.09 \pm 5.32^{\mathrm{a}}$ \\
\hline \multirow{2}{*}{\multicolumn{3}{|c|}{ Sourdough fermentation* }} & $45.59 \pm 13.98^{\mathrm{b}}$ & $3.96 \pm 0.89^{\mathrm{a}}$ & $1.79 \pm 0.55^{\mathrm{a}}$ \\
\hline \multicolumn{2}{|c|}{ p-values } & & 0.01 & 0.38 & 0.16 \\
\hline
\end{tabular}
detected. "Values in the same column with different superscripts differ significantly $\mathrm{p}<0.05(\mathrm{n}=4)$. 
lactic acid bacteria able to dephosphorylate phytate, forming free inorganic phosphate and inositol phosphate esters (which have less capacity to influence mineral solubility and bioavailability) (Türk, Carlsson, \& Sandberg, 1996), (Lopez et al., 2003). Phytase action is accelerated by the production of lactic acid and decreases in $\mathrm{pH}$ to optimal levels for enzyme activity. In our study, the possibility for interaction between iron ions and bioaccessibility inhibitors was limited by the barrier formed by the microcapsule carriers. The presence or degradation of phytic acids had limited or no impact on iron bioaccessibility.

Another possible factor influencing Fe availability could be its state of oxidation. At intestinal $\mathrm{pH}$ ferric iron is insoluble, while ferrous iron is still soluble. To absorb ferric iron, it should be reduced to ferrous iron by ferrireductase and transported through an active transport process involving DMT-1 (divalent metal transporter-1). Speciation of the different oxidation states of iron in the soluble fractions of the digestates revealed that during digestion iron was released from the microcapsules and Fe(II) was oxidized either partially (CFM1, SFM1CFM2, CFM3, CHM4) or even completely (SFM2, SFM3, SFM4). Ferric ions were the main form detected in the soluble fraction of the digestates of breads made by sourdough fermentation (Fig. 1). Fe(II) was detected almost exclusively in the digested samples of breads prepared by conventional fermentation. Chemical and physical changes due to the presence of sourdough in the bread formulation seem to have induced an environment leading to a higher degree of iron oxidation.

Iron absorption may be enhanced by simultaneous intake of vitamin C, and animal protein (Hurrell \& Egli, 2010). Ascorbic acid which is a potent iron availability enhancer was used in the current studies, although it is a heat sensitive compound and baking may cause decomposition from 55 to 80\%. (Wang, Seib, \& Ra, 1995) (Park, Seib, Chung, \& Seitz, 1997). Regardless of the fermentation type, no signs of the protective impact of ascorbic acid against the oxidation of ferrous ions was observed during the digestion period (breads fortified with M2 and M4). Presence of Fe(II) in the digestates of breads prepared using sourdough was not detected or in concentration lower in comparison with corresponding bread but prepared with conventional fermentation (SFM1 and CFM1), possibly due to the oxidation of ascorbic acid in the preparation process. The dough was incubated for $24 \mathrm{~h}$, at $30{ }^{\circ} \mathrm{C}$ and probably the conditions induced faster ascorbic acid decomposition. It was established that stability of ascorbic acid in cereal-based products is dependent on time, temperature and product moisture (Stešková, Morochovičová, \& Lešková, 2006).

The microencapsulated iron added to the breads was maintained in soluble form after the bread-making process and presumably resisted the gastric conditions of a human adult.

\subsection{Simulated intestinal absorption - iron bioavailability}

Studies of compound bioavailability are designed to trace the changing state of compounds during digestion (bioaccessibility) and absorption. The bioaccessibility of a compound can be defined as the quantity or fraction of that substance which is released from the food matrix in the gastrointestinal tract, becoming available for absorption and transportation around the body (Heaney, 2001)' (Holst \& Williamson, 2008). The absorption of iron by Caco- 2 cells after simulated gastric and small intestinal digestion was used to assess bioavailability. Two iron absorption parameters were calculated:

$$
\begin{aligned}
\% \text { Transport }= & \frac{\text { soluble iron (ionic Fe) in the basal media }[\mu \mathrm{g}]}{\text { applied iron on apical media }[\mu \mathrm{g}]} \times \\
& 100 \%
\end{aligned}
$$

$\%$ Transport efficiency $=\frac{\% \text { bioaccesibility } \times \% \text { Transport }}{100}$

The percentage of iron transport and transport efficiency showed no significant statistical differences between the fermentation type ( $\mathrm{p}>0.05$ ). The parameters showed no significant statistical differences as well between iron sources (iron transport [\%]: $8.24 \pm 3.26$; $7.01 \pm 0.77$ and iron transport efficiency [\%]: $5.83 \pm 2.04$, $5.47 \pm 1.21$ for ferrous sulphate and lactate, respectively). The percentage of iron transport efficiency varied widely, in a range from 1.16 to 13.78 (Table 2). This large spread of results was due mainly to the results obtained for CFM2. In comparison with other samples, CFM2 showed notably higher iron transport efficiency (13.78\%), exceeding by nearly 3 times the efficiency observed for sample CFM1 fortified as well with ferrous sulphate. This difference is probably a result of the presence of vitamin $C$ in microcapsule 2 . The antioxidative properties of this vitamin preserve iron in the divalent form, which is considered to be more available for transport by enterocytes (Hemalatha, Platel, \& Srinivasan, 2007). These results are in agreement with others described in the literature. Frontela et al. presented an in vitro study of iron transport efficiency using Caco-2 cells from children's cereals (Frontela, Scarino, Ferruzza, Ros, \& Martínez, 2009). The iron transport efficiency of eight cereals, honey, multicereals, rice cream and gluten-free meals was in the range of $0.14 \%-2.21 \%$. Efficiency was increased to $1.47 \% \div$ $6.02 \%$ when the samples were treated with phytase. CFM1, CFM3 and CFM4 presented iron transport efficiency in the similar range than the children's cereals. The transport efficiency from CFM2 was about twice as high as in the compared research. A comparison of different baking processes suggests that iron was more effectively transported from fortified bread prepared by conventional fermentation, with the

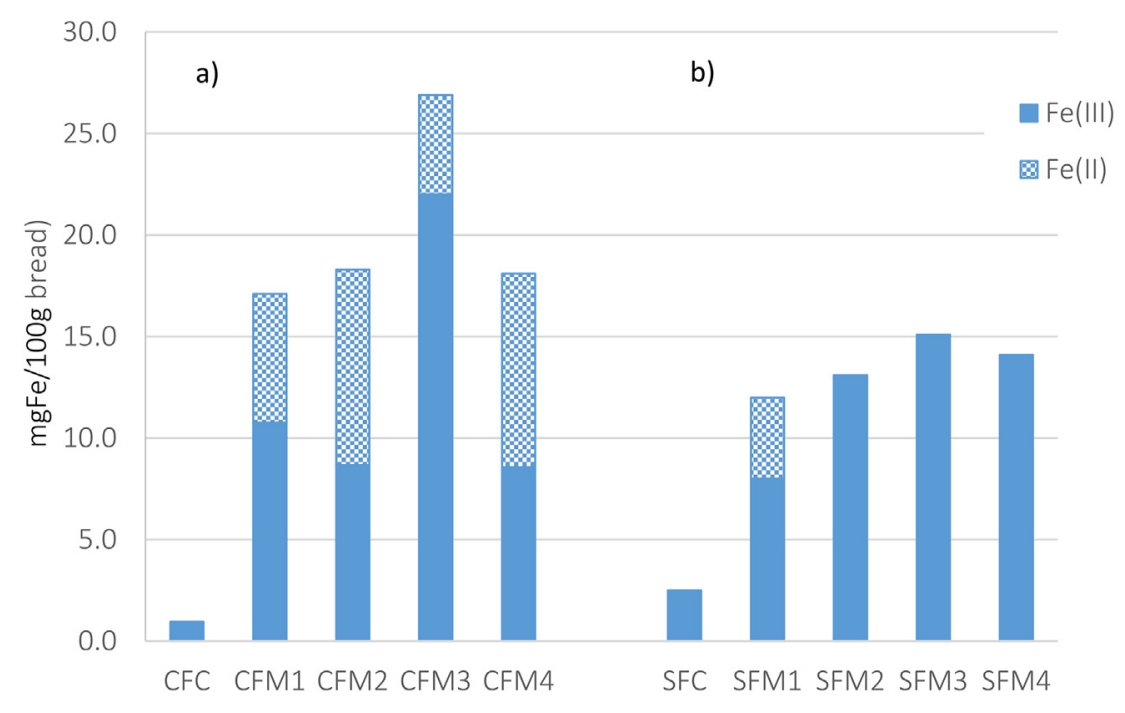

Fig. 1. Ionic iron speciation in digestates of fortified breads prepared using a) conventional fermentation (CFM1-4) or b) sourdough (SFM1-4). The $\mathrm{Fe}(\mathrm{II})$ and $\mathrm{Fe}(\mathrm{III})$ contents in the digestates were measured after $8 \mathrm{~h}$ of digestion in a dynamic gastrointestinal digester under condition mimicking the upper gastrointestinal tract of a human adult. 


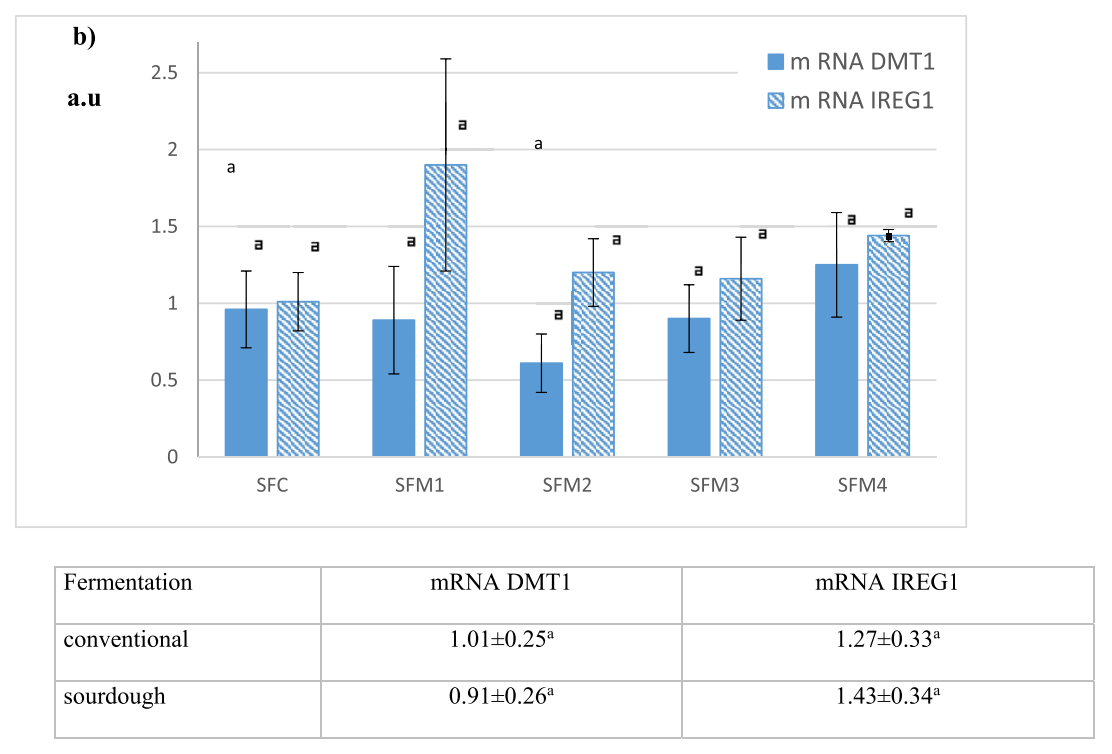

\begin{tabular}{|l|c|c|}
\hline Ferrous & mRNA DMT1 & mRNA IREG1 \\
\hline sulphate & $0.84 \pm 0.27^{\mathrm{a}}$ & $1.49 \pm 0.40^{\mathrm{a}}$ \\
\hline lactate & $1.08 \pm 0.16^{\mathrm{a}}$ & $1.20 \pm 0.20^{\mathrm{a}}$ \\
\hline
\end{tabular}

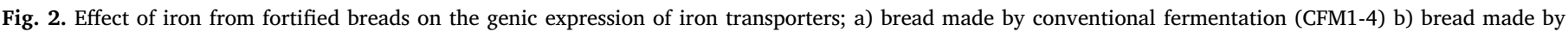
sourdough fermentation (SFM1-4). Values in the same row with different superscripts differ significantly $\mathrm{p}<0.05$ (n $=4$ ).

exception of CFM4, where the method of fermentation seems to have had no impact on iron transport. In the breads made with sourdough and with conventional yeast, of the iron sources investigated ferrous sulphate showed the highest transport efficiency.

The process of non-heme iron movement across the enterocyte brush border membrane was traced using molecular markers associated with transporters, DMT1 and IREG1. After the transport assay, mRNA expression was investigated for iron transporters, DMT1 (in the apical membrane) and IREG1 (in the basolateral membrane). Neither the mRNA expression of DMT1 nor that of IREG1 showed statistical significance between type of iron source or fermentation type. The mRNA expression of IREG1 was at a similar level in the majority of the samples. Expression over that level was observed for CFM2 and SFM1 (Fig. 2). These results are in line with others reported in the literature, and may be because the regulation of DMT1 mRNA is slower than protein regulation, since mRNA expression is observed after 48 or $72 \mathrm{~h}$ (Sharp et al., 2002). A second possible explanation is the tendency for increased mRNA expression of IREG1 in CFM2 and CFM3. The overexpression of ferroportin (IREG1) in HEK293T cells has been described as reducing ferritin synthesis (Thomas \& Oates, 2004). The same relation was observed by Martini, Tchack, \& Wood, 2002, who observed that iron treatment downregulated DMT1 and IREG1 mRNA expression in Caco- 2 cells. In their study, Caco- 2 cells treated with a high concentration of iron showed an increase in intracellular ferritin and a decrease in the mRNA of DMT1, despite a long period of iron treatment lasting $72 \mathrm{~h}$.

\section{Conclusions}

Iron fortified breads offer an alternative source of this element for the treatment of iron deficiency. In this study, the bioaccessibility and bioavailability of iron in breads made by yeast or sourdough fermentation were investigated using combined technologies: a dynamic in vitro gastrointestinal system to reproduce gastrointestinal digestion (bioaccesibility) and the human colonic adenocarcinoma (Caco-2) cell line, as a model of intestinal absorption (bioavailability). Iron absorption and accessibility for intestinal transport can be improved by creating a stable barrier between the compound and food matrix, which can contain bioavailability inhibitors. As a technological adaptation of iron fortification, encapsulation seems to provide an effective way of minimizing or almost completely avoiding the immobilization of iron on its food matrix. Our results show that after $6 \mathrm{~h}$ of digestion, from $35.99 \%$ to nearly $100 \%$ of the iron was in the soluble form, ready for absorption. The proposed form of iron encapsulation in modified starch as a carrier gave a better effect when was used for conventional bread fortification. The type of iron source, ferrous sulphate or ferrous lactate, in the microcapsules had impact on the tested parameters however the differences were not statically significant. Encapsulation therefore seems to be an effective method for fortifying food with iron.

\section{Conflicts of interest}

The authors declare that they have no conflict of interest.

\section{Acknowledgments}

This work was funded by European Union's Seventh Framework Program managed by REA-Research Executive Agency http://ec. europa.eu/research/rea (FP7/2007-2013) under grant agreement n.606476.

\section{References}

Benito, P., \& Miller, D. (1998). Iron absorption and bioavailability: An updated review. Nutrition Research, 18(3), 581-603.

Blanco-Rojo, R., \& Vaquero, M. P. (2018). Iron bioavailability from food fortification to precision nutrition. A review. Innovative Food Science \& Emerging Technologies (in press).

Brune, M., Rossander-Hultén, L., Hallberg, L., Gleerup, A., \& Sandberg, A. S. (1992). Iron absorption from bread in humans: Inhibiting effects of cereal fiber, phytate and inositol phosphates with different numbers of phosphate groups. Journal of Nutrition, 122(3), 442-449.

Castillo-Duran, C., \& Ruz, M. (2004). Epidemiology of micronutrient deficiencies in 
developing and developed countries, specifically zinc, copper, selenium and iodine. Micronutrient deficiencies during the weaning period and the first years of life. Nestlé Nutrition Workshop Series Pediatric Program, 54, 37-52.

Donovan, A., Lima, C. A., Pinkus, J. L., Pinkus, G. S., Zon, L. I., Robine, S., et al. (2005). The iron exporter ferroportin/Slc40a1 is essential for iron homeostasis. Cell Metabolism, 1(3), 191-200.

Fairweather-Tait, S., Lynch, S., Hotz, C., Hurrell, R., Abrahamse, L., Beebe, S., et al. (2005). The usefulness of in vitro models to predict the bioavailability of iron and zinc: A consensus statement from the HarvestPlus expert consultation. International Journal for Vitamin and Nutrition Research, 75, 371-374.

Frontela, C., Scarino, M.-L., Ferruzza, S., Ros, G., \& Martínez, C. (2009). Effect of dephytinization on bioavailability of iron, calcium and zinc from infant cereals assessed in the Caco-2 cell model. World Journal of Gastroenterology, 15(16), 1977-1984.

Ganz, T. (2013). Systemic iron homeostasis. Physiological Reviews, 93(4), 1721-1741.

Gaucheron, F. (2000). Iron fortification in dairy industry. Trends in Food Science \& Technology, 11(11), 403-409.

Gera, T., Sachdev, H. S., \& Boy, E. (2012). Effect of iron-fortified foods on hematologic and biological outcomes: Systematic review of randomized controlled trials. American Journal of Clinical Nutrition, 96(2), 309-324.

Gharibzahedi, S. M. T., \& Jafari, S. M. (2017). The importance of minerals in human nutrition: Bioavailability, food fortification, processing effects and nanoencapsulation. Trends in Food Science \& Technology, 62, 119-132.

Heaney, R. P. (2001). Factors influencing the measurement of bioavailability, taking calcium as a model. Journal of Nutrition, 131(4) 1344S-8S.

Hemalatha, S., Platel, K., \& Srinivasan, K. (2007). Zinc and iron contents and their bioaccessibility in cereals and pulses consumed in India. Food Chemistry, 102(4), 1328-1336.

Hennessy, D. J., Reid, G. R., Smith, F. E., \& Thompson, S. L. (1984). Ferene - a new spectrophotometric reagent for iron. Canadian Journal of Chemistry, 62(4), 721-724.

Holst, B., \& Williamson, G. (2008). Nutrients and phytochemicals: From bioavailability to bioefficacy beyond antioxidants. Current Opinion in Biotechnology, 19(2), 73-82.

Hurrell, R. F. (1997). Preventing iron deficiency through food fortification. Nutrition Reviews, 55(6), 210-222.

Hurrell, R., \& Egli, I. (2010). Iron bioavailability and dietary reference values. American Journal of Clinical Nutrition, 91(5), 1461S-1467S.

Hurrell, R. F., Reddy, M. B., Juillerat, M.-A., \& Cook, J. D. (2003). Degradation of phytic acid in cereal porridges improves iron absorption by human subjects. American Journal of Clinical Nutrition, 77(5), 1213-1219.

International Association of Plant Bakers AISBL. reportAIBI Bread Market Report 2013. http://www.aibi.eu/wp-content/uploads/draft-AIBI-Bread-Market-report-2013.pdf.

International Zinc Nutrition Consultative Group (IZiNCG) Technical document \#1. Assessment of the risk of zinc deficiency in populations and options for its control (2004). Food and Nutrition Bulletin, 25(1 Suppl 2), S99-S203.

Khouzam, R. B., Pohl, P., \& Lobinski, R. (2011). Bioaccessibility of essential elements from white cheese, bread, fruit and vegetables. Talanta, 86, 425-428.

Lopez, H. W., Duclos, V., Coudray, C., Krespine, V., Feillet-Coudray, C., Messager, A., et al. (2003). Making bread with sourdough improves mineral bioavailability from reconstituted whole wheat flour in rats. Nutrition, 19, 524-530.

Marteau, P., Flourie, B., Pochart, P., Chastang, C., Desjeux, J. F., \& Rambaud, J. C. (1990) Effect of the microbial lactase (EC 3.2.1.23) activity in yoghurt on the intestinal absorption of lactose: An in vivo study in lactase-deficient humans. British Journal of Nutrition, 64(1), 71-79.

Martini, L. A., Tchack, L., \& Wood, R. J. (2002). Iron treatment downregulates DMT1 and IREG1 mRNA expression in Caco-2 cells. Journal of Nutrition, 132(4), 693-696.

Minekus, M., Marteau, P., Havenaar, R. et al. Marteau, P., Havenaar, R., Huis in t Veld, J. H. H. (1995). A multicompartmental dynamic computercontrolled model simulating the stomach and small intestine. Alternatives to Laboratory Animals: ATLA, 23 197-209.

Minekus, M., Smeets-Peeters, M., Bernalier, A., Marol-Bonnin, S., Havenaar, R., Marteau, et al. (1999). A computer-controlled system to simulate conditions of the large intestine with peristaltic mixing, water absorption and absorption of fermentation products. Applied Microbiology and Biotechnology, 53(1), 108-114.

Nemeth, E., Tuttle, M. S., Powelson, J., Vaughn, M. B., Donovan, A., Ward, D. M., et al. (2004). Hepcidin regulates cellular iron efflux by binding to ferroportin and inducing its internalization. Science, 306(5704), 2090-2093.

Okhee, H. (2011). Molecular mechanism of intestinal iron absorption. Metall, 3(2), 103-109.

Park, H., Seib, P. A., Chung, O. K., \& Seitz, L. M. (1997). Fortifying bread with each of three antioxidants. Cereal Chemistry, 74, 202-206.

Rivera, D., Gallego, E., Villalba, M., \& Gianotti, A. (2014). Innovative iron fortified bakery products. Microencapsulation technology to improve iron bioaccessibility of enriched bread products. Functional Bakery Products, 8-15

Sharp, P., Tandy, S., Yamaji, S., Tennant, J., Williams, M., \& Singh Srai, S. K. (2002). Rapid regulation of divalent metal transporter (DMT1) protein but not mRNA expression by non-haem iron in human intestinal Caco-2 cells. FEBS Letters, 510(1-2), $71-76$.

Stešková, A., Morochovičová, M., \& Lešková, E. (2006). Vitamin C degradation during storage of fortified foods. Journal of Food and Nutrition Research, 45(2), 55-61.

Tandara, L., \& Salamunic, I. (2012). Iron metabolism: Current facts and future directions. Biochem Med (Zagreb), 22(3), 311-328.

Tandy, S., Williams, M., Leggett, A., Lopez-Jimenez, M., Dedes, M., Ramesh, B., et al. (2000). Nramp2 expression is associated with $\mathrm{pH}$-dependent iron uptake across the apical membrane of human intestinal Caco-2 cells. Journal of Biological Chemistry, 275(2), 1023-1029.

Tapia, V., Arredondo, M., \& Núñez, M. T. (1996). Regulation of Fe absorption by cultured intestinal epithelia (Caco-2) cell monolayers with varied Fe status. American Journal of Physiology, 271(3 Pt 1), G443-G447.

Thomas, C., \& Oates, P. S. (2004). Ferroportin/IREG-1/MTP-1/SLC40A1 modulates the uptake of iron at the apical membrane of enterocytes. Gut, 53(1), 44-49.

Türk, M., Carlsson, N. G., \& Sandberg, A. S. (1996). Reduction in the levels of phytate during wholemeal bread making: Effect of yeast and wheat phytases. Journal of Cereal Science, 23, 257-264.

USDA Food Composition Databases (2017). Nutrients list, iron. https://ndb.nal.usda.gov/ $\mathrm{ndb} /$ nutrients/report? nutrient $1=303 \&$ nutrient $2=\&$ nutrient $3=\& \mathrm{fg}=18 \& \mathrm{max}=25 \&$ subset $=0$ \&offset $=125 \&$ sort $=$ f\&totCount $=842 \&$ measureby $=g$.

Wang, X. Y., Seib, P. A., \& Ra, K. S. (1995). L-Ascorbic acid and its 2-phosphorylated derivatives in selected foods: vitamin $\mathrm{C}$ fortification and antioxidant properties. Journal of Food Science, 60(6), 1295-1300.

World Development Report (1993). Investing in health. Oxford: World Bank, Oxford University Press. https://openknowledge.worldbank.org/handle/10986/5976.

World Health Organization (WHO) (2001). Iron deficiency anaemia: Assessment, prevention and control: A guide for programme managers. http://www.who.int/nutrition/ publications/en/ida_assessment_prevention_control.pdf.

World Health Organization (WHO) (2015). Worldwide prevalence of anaemia 1993-2005. http://apps.who.int/iris/bitstream/handle/10665/43894/9789241596657_eng.pdf? sequence $=1$.

Zimmermann, M. B., \& Hurrell, R. F. (2007). Nutritional iron deficiency. The Lancet, 370(9586), 511-520.

Zlotkin, S., Arthur, P., Antwi, K. Y., \& Yeung, G. (2001). Treatment of anemia with microencapsulated ferrous fumarate plus ascorbic acid supplied as sprinkles to complementary (weaning) foods. American Journal of Clinical Nutrition, 74(6), 791-795. 